\title{
Caracterização físico-química da seriguela (Spondias purpurea L.) colheitadas no município de Barra do Bugres/MT em diferentes estágios de maturação
}

A seriguela (Spondias purpúrea L.) é comumente cultivada no Nordeste brasileiro, sendo uma fruta que se adapta a diferentes temperaturas e é de fácil cultivo, tanto em solos drenados ou secos. Das diversas espécies que compõe o gênero Spondias, a seriguela se destaca, sendo rica em componentes nutricionais benéficos a saúde, como a vitamina C, fonte de fibras, razoável teor de calorias e baixo teor de gordura e proteínas. Sua comercialização é regionalmente feita de forma in natura. Apesar de conter um caroço consideravelmente grande, apresenta um rendimento em polpa $>50 \%$, o que comprova uma forte potencialidade no processamento industrial, podendo ser utilizada na elaboração de bebidas fermentadas, geleias, sucos, vinhos, compotas, sorvetes, licores e refrigerantes. Porém, as frutas apresentam variações nas características físico-químicas conforme o local de colheita e estágio de maturação. Diante disso, esta pesquisa teve como objetivo a caracterização físico-química da seriguela colheitada em diferentes estágios de maturação. As frutas foram colheitadas em três localidades diferentes do município de Barra do Bugres, MT nos estágios verde, de vez e maduro. As seriguelas foram higienizadas em água corrente abundante, descascadas e despolpadas. As cascas e polpas foram analisadas em relação a acidez total titulável, cinzas, umidade, pH sólidos solúveis e vitamina C. Assim, a pesquisa mostrou que conforme o avanço da maturação o pH aumentou para todas as colheitas e, consequentemente a acidez aumentou como também o teor de vitamina C e sólidos solúveis totais aumentaram. Devido a troca osmótica a casca transferiu umidade para a polpa. Em relação ao teor de resíduo mineral fixo a casca foi a que apresentou maior teor para todas as colheitas.

Palavras-chave: Solo de cultivo; Fatores genéticos; Fruta sazonal.

\section{Physical-chemical characterization of seriguela (Spondias purpurea L.) collected in the municipality of Barra do Bugres/MT at different maturation}

\section{stages}

The seriguela (Spondias purpúrea L.) is commonly cultivated in the Northeast of Brazil, being a fruit that adapts to different temperatures and is easy to grow, both in drained and dry soils. Of the several species that make up the genus Spondias, seriguela stands out, being rich in nutritional components beneficial to health, such as vitamin C, fiber source, reasonable calorie content and low fat and protein content. Its commercialization is regionally made in nature form. Although it contains a very large core, it has a pulp yield of $>50 \%$, which proves a strong potential in industrial processing. It can be used in the elaboration of fermented beverages, jellies, juices, wines, jams, ice creams, liqueurs and soft drinks. However, the fruits present variations in the physical-chemical characteristics according to the place of harvest and stage of maturation. In view of this, this research had as objective the physical-chemical characterization of the seriguela collected in different stages of maturation. The fruits were collected in three different locations of the municipality of Barra do Bugres, MT in the green stadiums, from time to time. The seriguelas were sanitized in abundant running water, peeled and depulped. The peels and pulps were analyzed for total titratable acidity, ashes, moisture, $\mathrm{pH}$, soluble solids and vitamin $\mathrm{C}$. Thus, the research showed that as the maturity progressed the $\mathrm{pH}$ increased for all the collections and, consequently, the acidity increased as also the vitamin C content and total soluble solids increased. Due to the osmotic exchange the shell transferred moisture to the pulp. Regarding the fixed mineral residue content, the bark presented the highest content for all collections.

Keywords: Cultivation only; Genetic factors; Seasonal fruit.

Topic: Ciência de Alimentos

Reviewed anonymously in the process of blind peer.

Thamires Santos Neris

Universidade do Estado do Mato Grosso, Brasil

http://lattes.cnpq.br/8428264721265256

thamires nerisbbu@hotmail.com

Raquel Aparecida Loss

Universidade do Estado do Mato Grosso, Brasil

http://lattes.cnpq.br/3925129970802016

raquelloss@unemat.br

Sumaya Ferreira Guedes

Universidade do Estado do Mato Grosso, Brasil

http://lattes.cnpq.br/8709866585453750

http://orcid.org/0000-0001-7901-1316

su_sumaya@yahoo.com.br

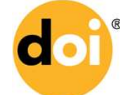

DOI: 10.6008/SPC2237-9290.2017.001.0002
Received: 16/07/2017

Approved: 19/10/2017
Referencing this:

NERIS, T. S.; LOSS, R. A.; GUEDES, S. F.. Caracterização físico-química da seriguela (Spondias purpurea L.) colheitadas no município de Barra do Bugres/MT em diferentes estágios de maturação. Natural Resources, v.7, n.1, p.9-18, 2017. DOI: http://doi.org/10.6008/SPC2237-9290.2017.001.0002 


\section{INTRODUÇÃO}

O Brasil, em virtude da sua larga extensão territorial e ampla mudança climática, ostenta uma das maiores variedades de espécies de frutas do mundo, destacando as regiões Nordeste e Norte que oferecem condições climatéricas apropriadas para cultivar muitas frutas tropicais (FILHO, 2007). Segundo Lederman et al. (2008) a quantidade média comercializada nos períodos entre 2000 a 2006 na CEASA (Centro de Abastecimento) do Estado de Pernambuco foi de 585ton de seriguela, sendo que, cerca de $75 \%$ desse total, era proveniente do Ceará.

O consumo periódico de frutas está relacionado a diminuição do risco de câncer, como também de doenças como o Alzheimer, cardiovasculares, cataratas e de alguns decréscimos relacionados ao envelhecimento. Estudos comprovam, que diversos frutos, tais como a seriguela, possuem fotoquímicos, dentre eles os flavonoides e compostos fenólicos que são essenciais para a saúde e cuidado dos tecidos celulares e prevenção de doenças ligadas a uma alimentação inadequada (INCA, 2007).

A seriguela é uma fruta tropical que apresenta de alta perecibilidade durante a manipulação póscolheita, susceptível ao amolecimento e consequentemente atingindo com rapidez a senescência, de modo a alterar o seu sabor. Por esse motivo, as indústrias vêm investindo crescentemente em novas técnicas que visam prolongar a vida útil de frutas sazonais como a seriguela (SAUCEDO-VELOZ et al., 2004).

Dentro desse contexto, a presente pesquisa se dispõe avaliar as características físico-químicas da casca e da polpa da seriguela in natura em três estágios de maturação (verde, de vez e maduro). Além disso, buscou demonstrar se houve diferenças em suas propriedades em relação aos diferentes locais em que foram colheitadas.

\section{METODOLOGIA}

\section{Obtenção e preparo da matéria-prima}

As frutas de seriguela foram colheitadas no município de Barra do Bugres/MT em três diferentes locais da cidade. A primeira colheita foi realizada na parte da cidade localizada a 2,4 km de distância da UNEMAT, conforme mostra a figura 1A; a segunda e terceira colheitas foram feitas em partes rurais do município, sendo o rural 1 localizado a 5,8 km, demonstrado na figura 1B, e o rural 2 a 18,7 km de distância da faculdade, de acordo com o ilustrado na figura 1C. As colheitas das frutas foram realizadas ao longo de 15 dias, uma vez que as frutas foram colhidas já nos estágios de maturação analisados.

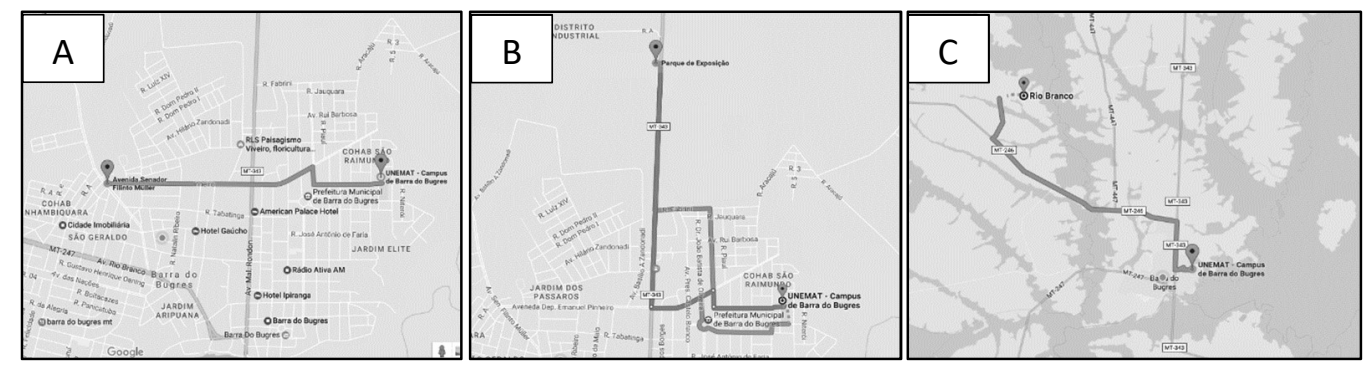

Figura 1: Locais de colheita das seriguelas. A - Cidade; B - Rural 1; C - Rural 2. 
Os frutos foram acondicionados, refrigerados e transportados para o laboratório de Química da Universidade do Estado de Mato Grosso (UNEMAT), onde foram higienizados com solução de hipoclorito de sódio $5 \mathrm{mg} / \mathrm{L}$ por 10 minutos e lavados em água corrente abundante. As amostras sanitizadas foram separadas em três partes: polpa, casca e semente, em seguida foram processadas até obter uma mistura homogênea para posteriores análises. A Figura 2 apresenta um fluxograma da obtenção e preparo para amostragem da seriguela. As amostras da polpa e casca trituradas foram congeladas a $-18^{\circ} \mathrm{C}$ até o momento das análises físico químicas.

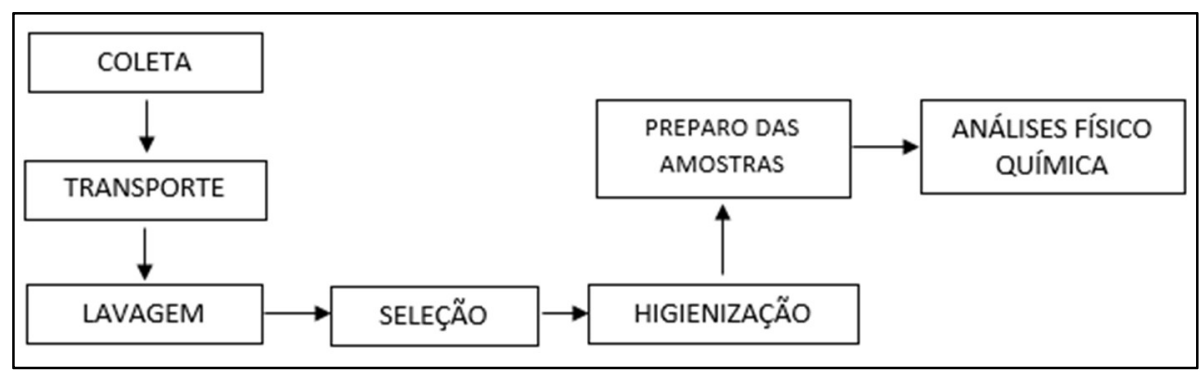

Figura 2: Obtenção e preparo para amostragem da seriguela.

\section{Análise Físico-químicas da Seriguela in natura}

A polpa e casca da seriguela in natura, nos diferentes estágios de maturação (verde, de vez e madura) e locais de colheita (cidade, rural 1 e rural 2) foram analisados em relação ao pH, acidez em ácido cítrico, umidade, cinzas, sólidos solúveis totais e Vitamina C, segundo a metodologia descrita pelo Instituto Adolfo Lutz (2008).

\section{RESULTADOS E DISCUSSÕES}

$\mathrm{O} \mathrm{pH}$ é um dos fatores importantes que implicam diretamente tanto nas características sensoriais como nutricionais de um alimento. De modo geral, alimentos que apresentam um teor de acidez elevado possui consequentemente um pH baixo. Alimentos ácidos normalmente não apresentam elevada aceitação para seu consumo na forma in natura, uma vez que apresenta palatabilidade não tão agradável (SOARES, 2009). Assim sendo, foram realizadas análises de pH da casca e da polpa da seriguela, no intuito de correlacionar as características que cada uma apresenta entre seus estágios de maturação e localidades de colheita, conforme ilustrado na figura 3.

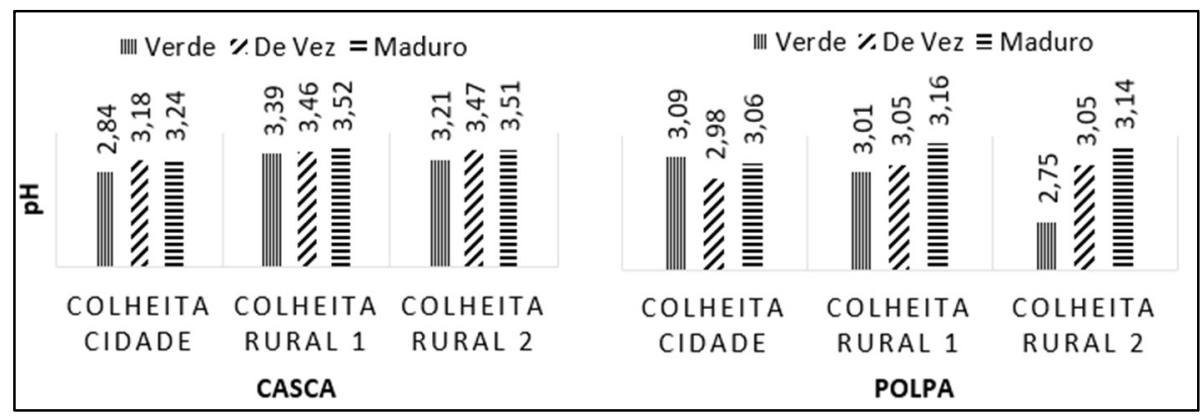

Figura 3: $\mathrm{pH}$ da casca e polpa da seriguela in natura em diferentes estágios de maturação e localidade. 
Pela figura 3 observa-se que, de maneira geral, o pH independentemente do local de colheita, tanto para a casca quanto para a polpa não diferenciaram de maneira acentuada. A polpa verde da colheita rural 2 apresentou o menor valor de $\mathrm{pH}(2,75)$ e a casca madura das colheitas rurais apresentaram o maior teor de $\mathrm{pH}(3,52)$. Observa-se também, que com exceção da polpa colhida na cidade, independentemente do local da colheita, tanto a casca quanto a polpa verde apresentaram maior acidez e, à medida que o fruto ia amadurecendo a acidez reduziu. Chitarra et al. (2001), constataram que conforme o amadurecimento da fruta o $\mathrm{pH}$ amentou.

Ao analisar seriguelas Diaz-Perez et al. (1998) encontraram também valores mais altos de $\mathrm{pH}$ nas frutas maduras, fato comprovado por Martins et al. (2003), que obtiveram valores entre 3,34 e 3,44 para as seriguelas no estágio de maturação de vez e maduras, respectivamente.

Segundo Chitarra et al. (2005), a acidez presente nas hortaliças é dada, sobretudo, pelos ácidos orgânicos dispersos nos vacúolos das células. $O$ ácido málico e o cítrico são os de maior abundância presente nas frutas, que dependendo da espécie se predomina em maior quantidade, como também é um dos principais parâmetros responsáveis pelo "flavor" e pela doçura. A figura 4 apresenta o teor da acidez em ácido cítrico presente na casca e polpa da fruta in natura, em diferentes estágios de maturação e localidades.

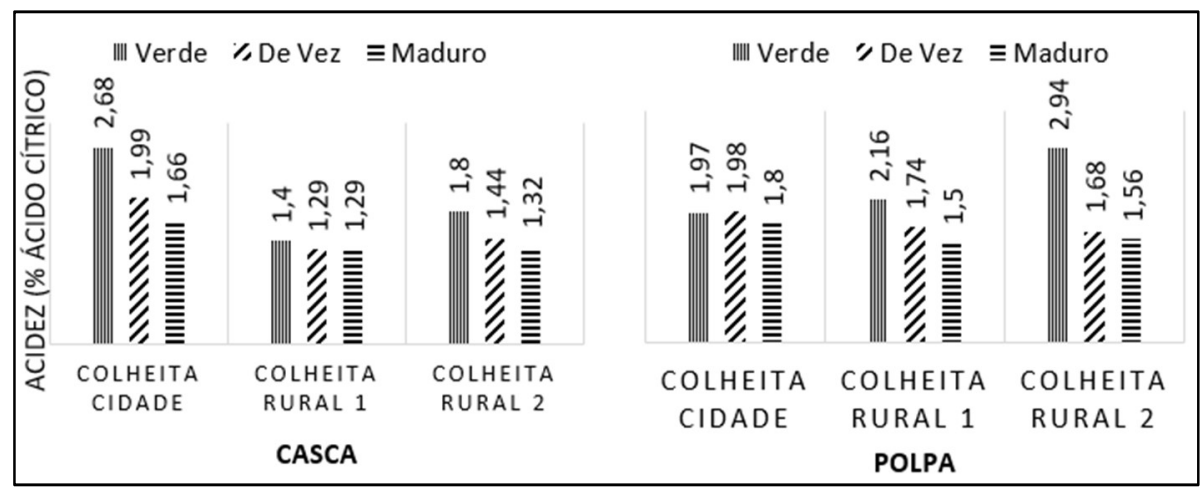

Figura 4: Acidez da casca e polpa da seriguela in natura em diferentes estágios de maturação e localidade.

Pela figura 4, nota-se que a casca da fruta colheitada na cidade, com exceção do estágio de maturação verde, foi a que apresentou uma acidez mais elevada em relação as outras colheitas e estágio de maturação, com valores de 2,68 \%, 1,99 \% e 1,66 \%, para os estágios de maturação verde, de vez e maduro, respectivamente. No estágio verde, a polpa da seriguela da colheita rural 2 foi a que apresentou o maior teor de acidez (2,94\%).

De maneira geral, a acidez em ácido cítrico, independentemente do local de colheita, reduziu com o amadurecimento, o que está de acordo com os resultados do $\mathrm{pH}$ que aumentaram à medida que a fruta amadureceu. Filgueiras (2001) também observou que conforme o amadurecimento, a acidez da seriguela diminuiu consideravelmente. Na maioria das frutas, a redução no teor de ácidos orgânicos durante o amadurecimento, ocorre em virtude da conversão em açúcares e do processo de respiração (CHITARRA et al., 2001).

Segundo Soares (2009), fatores relacionados a disponibilidade de água presente no solo e época de colheita podem ser parâmetros determinantes nos teores de acidez e pH. Assim sendo, esses resultados 
obtidos nas diferentes colheitas, podem estar relacionados diretamente a esses motivos, corroborando aos valores demonstrados na literatura.

A determinação do teor de umidade é uma das avaliações analíticas mais importantes na caracterização do alimento, como também, está diretamente ligada com a qualidade, composição e estabilidade, afetando principalmente a estocagem, o processamento e embalagens dos alimentos (CHAVES et al., 2004).

Assim como grande parte das frutas e hortaliças, a seriguela possui em sua composição grande quantidade de água livre, por essa razão, estão sujeitas a diversas modificações, tornando assim um meio favorável para alterações bioquímicas e químicas no processamento de alimentos. No entanto, para as indústrias de bebidas é considerado extremamente vantajoso, frutas que apresentem um alto teor de umidade. A Figura 5 apresenta a umidade da casca e polpa da fruta in natura, em diferentes estágios de maturação e localidades.

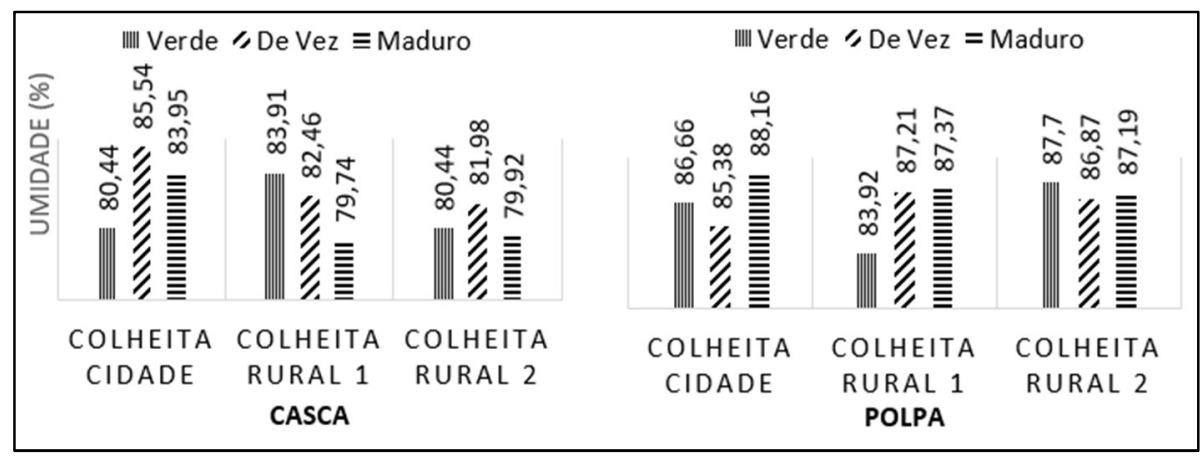

Figura 5: Umidade da casca e polpa da seriguela in natura em diferentes estágios de maturação e localidade.

Pela Figura 5, observa-se que na maioria dos locais de colheita, a umidade aumentou da fruta verde para a fruta madura. Para a colheita rural 2, a umidade da polpa de seriguela não sofreu alteração com o amadurecimento. Já a casca apresentou uma redução de umidade à medida que a fruta foi amadurecendo.

Conforme o avanço da maturação, a água presente na casca da seriguela é transferida para a polpa, devido a troca osmótica, onde ocorre a conversão do amido em açúcares causando um aumento do teor de umidade da polpa, como consequência disso a casca perde sua firmeza (LIMA et al., 2012). Esse conceito pode ser observado na maioria das colheitas, uma vez que a umidade da polpa foi superior à da casca. Apenas na colheita da cidade, para a fruta no estágio de maturação de vez $(85,54 \%$ e $85,38 \%)$, e para a colheita rural 1 no estágio de maturação verde $(83,91 \%$ e $83,92 \%)$, o teor de umidade entre a polpa e a casca permaneceram similares.

O teor de resíduo mineral fixo (cinzas) é resultado da queima total da matéria orgânica, e os resíduos restantes são denominados como inorgânicos, em virtude da eliminação dos constituintes voláteis, quando submetidos a altas temperaturas, correspondendo a quantia de minerais presentes. Apesar destes não serem vistos como nutrientes, são considerados componentes essenciais que ajudam a manter um equilibro orgânico perfeito, que auxilia nos processos metabólicos e presente em praticamente todos os tecidos do corpo humano. Dessa maneira, é de interesse tanto para a indústria de alimentos quanto para os 
consumidores à sua presença na composição alimentar (GRANATO et al., 2009). A figura 6 representa o teor de cinzas da casca e polpa da fruta in natura, em diferentes estágios de maturação e localidades.

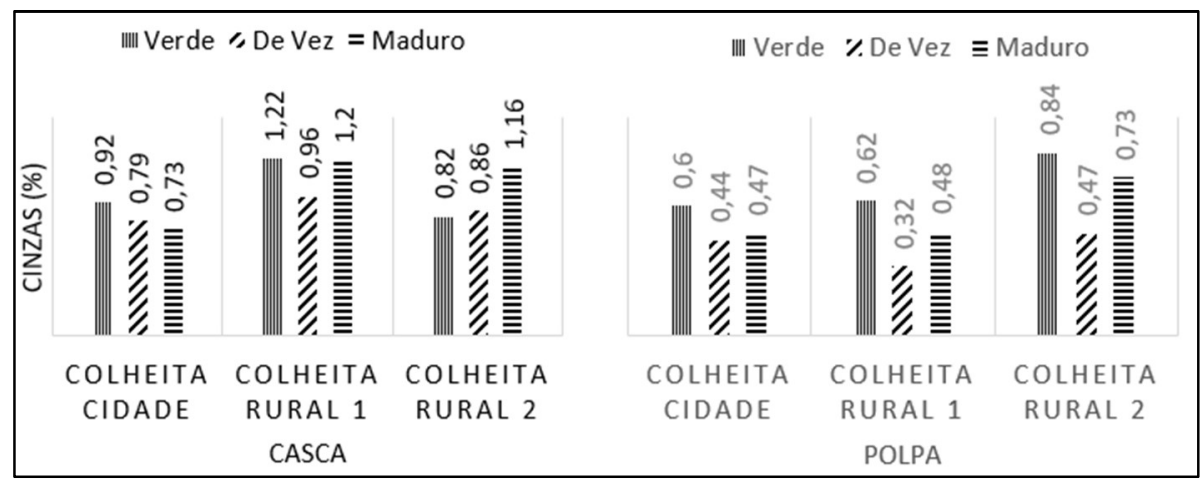

Figura 6: Teor de cinzas da casca e polpa da seriguela in natura em diferentes estágios de maturação e localidade.

Em relação ao teor de cinzas da casca, observou-se que a colheita da cidade foi a que apresentou menor valor nos estágios de vez e maduro, 0,79\% e 0,73\% respectivamente. Já a colheita da rural 1 foi a que expressou maiores quantias nos três estágios sendo 1,22\%, 0,96\% e 1,2\% (verde, de vez e maduro). Já para a polpa, notou-se que a colheita da rural 2 , no estágio verde obteve $0,84 \%$ de cinzas em relação as outras localidades no mesmo grau de maturação, como também foi a localidade que apresentou maiores valores para todos os estágios.

De modo geral, a presença de minerais é mais abundante nas cascas, folhas e talos das frutas e verduras, por isso, é de fundamental importância a ingestão com frequência (HARDISON et al. 2001). Assim, observa-se que a casca da seriguela apresentou teores maiores de minerais em relação a polpa. Os valores obtidos no presente estudo foram superiores aos encontrados por Monção et al. (2010) de 0,55\%. Essa variação de resultados pode ser em razão do genótipo da fruta, localidade de cultivo e grau de maturação.

A vitamina C é comumente encontrado em legumes, frutas e diversas verduras, desenvolvendo no metabolismo humano inúmeras funções e auxiliando no complemento de formação de colágeno como também na resistência orgânica, desempenho de ativação do crescimento e intervenção nas ações metabólicas da glicose e do ferro (FRANCO, 1992; LOPES et al., 1997).

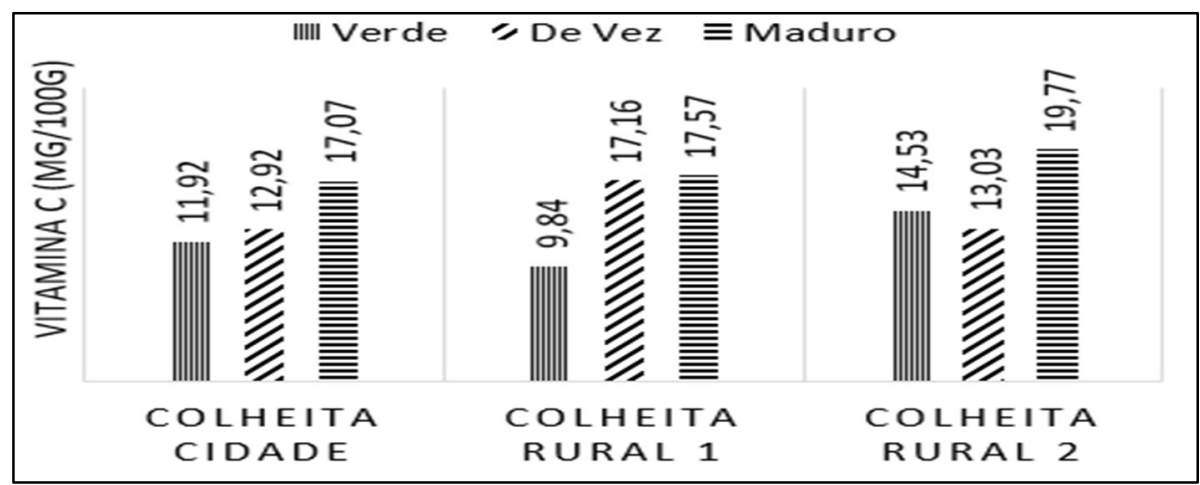

Figura 7: Teor de vitamina C na polpa da seriguela in natura em diferentes estágios de maturação e localidade.

A Figura 7 apresenta o teor de vitamina $C$ na polpa da fruta in natura, em diferentes estágios de maturação e localidades. Para a casca da seriguela, o teor de vitamina $C$ foi baixo, de modo que não foi 
possível quantificar com o método utilizado. A colheita rural 1 no estágio verde apresentou menor teor de vitamina em relação as das outras localidades, obtendo um valor de $9,84 \%$, enquanto a colheita da cidade e da rural 2 mostraram valores de 11,92\% e 14,53\%, consecutivamente. Já a polpa de vez colheitada na zona rural 1 foi a que apresentou maior teor de vitamina C, em relação as demais. No entanto, em vista do seu estágio maduro, mantiveram-se um perfil semelhante, não havendo variação significativa. Os valores obtidos nesta pesquisa estão de acordo com os estudos de Freire et al., (2011) variando entre 7,36 a 22,07mg/100g. para a coloração amarelo (estágio IV) e completamente vermelho (estágio V).

Pela figura 7, também é possível observar que conforme o avanço de maturação o teor de vitamina C aumentou, exceto para a colheita rural 2, que constatou uma redução no estágio de vez. Segundo MercadoSilva et al., (1998), o teor elevado de ácido ascórbico que ocorre durante o começo da maturação, os quais são precursores da vitamina $C$, se deve ao acréscimo da síntese dos metabólicos intermediários.

A quantia de sólidos solúveis totais (SST) presente em um fruto é determinada em ${ }^{\circ}$ Brix, aplicada para estabelecer o índice de maturação (ALVES, 1996). Os sólidos solúveis totais quantificam também a presença de substâncias dissolvidas na polpa da seriguela, sendo compostas de grande parte por açúcares, como também sais minerais, ácidos orgânicos, lipídeos, proteínas, pigmentos, glicídios, entre outros componentes fisiologicamente ativos.

Um dos parâmetros de maior interesse na determinação de qualidade de um fruto está relacionado ao seu rendimento, adquiridos das proporções do caroço, polpa e casca. De acordo com Chitarra et al. (2005), a quantidade entre o caroço (endocarpo), a polpa (mesocarpo) e casca (epicarpo) para algumas frutas é de grande relevância podendo ser aplicada, que somados com outras características como indicadores de rendimento da matéria-prima e índice de amadurecimento.

Araújo (2005) destaca que a correlação entre SST/ATT é um dos fatores mais aplicados para determinar o grau de amadurecimento de um fruto, sendo uma forma de indicar o período ideal para colheita deles, tendo em vista um amadurecimento apropriado. Esse é um dos parâmetros mais aplicados na avaliação do sabor, superando de forma mais representativa do que a análise individual de acidez ou de açúcares, sendo de grande utilidade para determinar a relação entre esses dois compostos (CHITARRA, 2005).

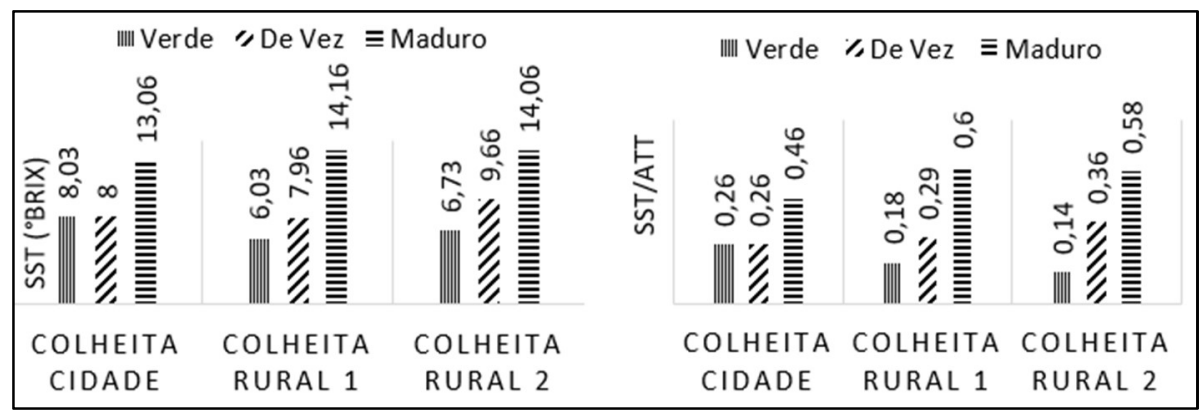

Figura 8: Teor de Sólidos Solúveis Totais e Relação SST/ATT na polpa da seriguela in natura em diferentes estágios de maturação e localidade.

A figura 8 apresenta o teor de sólidos solúveis totais ( ${ }^{\circ}$ Brix) e a relação SST/ATT (índice de maturação) das polpas de seriguela colheitadas em diferentes locais do município de Barra do Bugres e, em diferentes 
estágios de maturação. Pela figura 8 observa-se que a polpa verde da fruta colheitada na cidade apresentou uma média de $8,03^{\circ} \mathrm{Brix}$, valor elevado comparado aos das colheitas rurais 1 e 2 . Para todos os locais de colheita, o teor de sólidos solúveis totais foi aumentando conforme a fruta foi amadurecendo. Dessa forma, o teor de SST alcançou o máximo no fim da maturação, atribuindo um fruto de ótima qualidade.

A polpa madura da rural 1 foi a que maior apresentou um teor de SST em torno de $14,16^{\circ}$ Brix, não diferindo tanto da rural 2 (14,06 ${ }^{\circ}$ Brix). Resultados semelhantes aos encontrados por Nava Kuri et al. (1979), que ao estudarem frutos maduros obtiveram valores de SST entre $13^{\circ}$ Brix a $18^{\circ}$ Brix, ele foi visto por Martins et al. (2003). Como também aos achados por Omena et al. (2008), permanecendo na faixa de $6,23^{\circ} \mathrm{Brix}$ a 21,00 Brix. Lira Junior et al. (2010) ao estudar 11 genótipos clonadas de seriguela em Itambé-PE do Banco Ativo de Germoplasma, observaram uma média de $19,94^{\circ}$ Brix. Ao avaliar frutas em diferentes estágios de maturação, Freire et al. (2011), encontraram resultados de SST em torno $6,23^{\circ} \mathrm{Brix}$ e $21,2^{\circ} \mathrm{Brix}$, similar aos encontrados nessa pesquisa, que se manteve uma faixa entre os diferentes estágios e colheitas sendo de $6,03^{\circ}$ Brix a $14,16^{\circ}$ Brix.

A correlação entre SST/ATT, como pode-se constatar na Figura 8 aumentou significativamente conforme o avanço da maturação. Para as colheitas rurais observou-se um aumento gradativo desde o estágio verde até o maduro. Conforme a redução da acidez a presença de sólidos solúveis e consequentemente os índices de maturação aumentaram. Segundo Silva et al. (1998), a redução da acidez se deve a conversão em açúcares, sendo um fator desejável para a maioria dos frutos e de grande importância durante o seu processo de maturação.

De maneira geral, todas as análises físico químicas apresentaram variação nos diferentes locais de colheita pode ter sido influenciada por fatores extrínsecos e intrínsecos das condições de cultivo da serigueleira como por exemplo, a composição do solo, condições de crescimento, fatores genéticos, entre outros (CHITARRA, 2005). Além disso, de maneira geral, as características físico-químicas dos frutos de diferentes localidades podem apresentar variações na composição química e nutricional. E esta pode ser uma característica própria de plantas não domesticadas, como a seriguela (CANUTO, 2017).

\section{CONCLUSÕES}

De acordo, com as avaliações físico-químicas da seriguela in natura, pode-se constatar que conforme o amadurecimento a fruta foi perdendo acidez devido a conversão em açúcares e, consequentemente aumentando o pH. Em razão da troca osmótica, a umidade da casca reduziu com o avanço da maturação, causando assim maior teor na polpa. De modo geral, as cascas apresentaram maior conteúdo mineral em relação a polpa. $\mathrm{O}$ teor de vitamina $\mathrm{C}$ da polpa aumentou de acordo com o amadurecimento. $\mathrm{A}$ relação de sólidos solúveis totais com a acidez é inversamente proporcional, de modo que, conforme o teor de SST aumentou a acidez diminui, resultando no acréscimo gradativo do índice de maturação para todas as colheitas. 


\section{REFERÊNCIAS}

ALVES, R. E.. Características das frutas para exportação. In: Acerola para exportação: procedimentos de colheita e pós-colheita. Brasília: EMBRAPA, 1996.

ARAÚJO, F. P.. Potencialidades de fruteiras da caatinga. In: REUNIÃO NORDESTINA DE BOTÂNICA, 27. Anais. Petrolina: 2005.

ARAÚJO, F. P.; SILVA, G. C.; SANTOS, C. A. F.. Formação de raízes modificadas, tipo xilopódios em araticum (Annona coriacea Mart.). In: CONGRESSO NACIONAL DE BOTÂNICA, 53. Anais. Recife: UFPE, 2002

CANUTO, J. C.. Sistemas Agroflorestais: experiências e reflexões. Brasília: EMBRAPA, 2017.

CHAVES, M. C. V.; GOUVEIA, J. P. G.; ALMEIDA, F. A. C.; LEITE, J. C. A.; SILVA, L. H. S.. Caracterização físicoquímica do suco de acerola. Revista de Biologia e Ciências da Terra, v.4, n.2, 2004.

CHITARRA, A. B.; ALVES, R. E.. Tecnologia de póscolheita para frutas tropicais. Fortaleza: Instituto Frutal, v.1, 2001.

CHITARRA, M. I. F.; CHITARRA, A. B.. Pós-colheita de frutos e hortaliças: Fisiologia e manuseio. 2 ed. Lavras: UFLA, 2005.

DIAZ-PÉREZ, J. C.; ZAVALETA, R., BAUTISTA, S.; SEBASTIÁN, V.. Cambios Físico-Químicos de Ciriguela Mexicana (Spondeas purpúrea L.) cosechada em dos diferentes estados de madurez. Revista Iberoamericana de Tecnologia Postcosecha, v.1, 1998.

EMBRAPA. Empresa Brasileira de Pesquisa Agropecuária. Geração de Técnicas de Conservação Pós-Colheita para Valorização do Cultivo de Cajá e Ciriguela no Estado do Ceará. Fortaleza: EMBRAPA, 2001.

FILGUEIRAS, H. A. C.. Geração de Técnicas de Conservação Pós-Colheita Para Valorização do Cultivo de Cajá e Ciriguela no Estado do Ceará. Embrapa Agroindústria Tropical. Fortaleza: 2001.

FILHO, F. Q. T. L.. Conservação da Polpa de Cajá por Métodos Combinados. Dissertação (Mestrado em Ciências Agrárias) - Universidade Federal do Recôncavo da Bahia, Cruz das Almas, 2007.

FRANCO, G.. Nutrição: texto básico e tabela de composição química dos alimentos. 6 ed. Rio de Janeiro: Ateneu, 1992.

FREIRE, E. C. B. S.; SILVA, F. V. G.; SANTOS, A. F.; MEDEIROS, I. F.. Avaliação da qualidade de ciriguela
(Spondias purpurea, $L$ ) em diferentes estágios de maturação. Revista Verde, Mossoró, v.6, n.2, 2011.

GRANATO, D.; PIEKARSKI, F. V. B. W.; RIBANI, R. H.. Composição mineral de biscoitos elaborados a partir de farinhas de amêndoa ou amendoim adicionadas de ferro. Pesquisa Agropecuária Tropical, v.39, n.2, 2009.

HARDISON, A.; RUBIO, C.; BAEZ, A.; MARTIN, M.; ALVAREZ, R.; DIAZ, E.. Mineral composition of the banana (Musa acuminata) from the island of Tenerife. Food Chemistry, v.73, 2001.

IAL. Instituto Adolfo Lutz. Métodos Físico-Químicos para Análise de Alimentos. São Paulo: Instituto Adolfo Lutz, 2008.

INCA. Instituto Nacional do Câncer. Alimentos, nutrição, atividade física e prevenção de câncer: uma perspectiva global Rio de Janeiro: INCA, 2007.

LIMA, A. B. P.; ALVES, A. M. P.; ALMEIDA, F. G.; SOUZA, P. A. S.; SOUZA, J. P. C.; BARBOSA, M. C. F.. Avaliação das características físico-químicas de bananas desidratadas. Congresso Norte Nordeste de Pesquisa e Inovação, 7. Palmas, 2012.

LOPES, V. C.; MARTINS, M. H. B.; CARVALHO, I. T.. Teor de ácido ascórbico e dehidroascórbico em polpas de acerola (Malpighia glabra L.) congeladas e comercializadas na cidade do Recife - PE. Curitiba: 1997.

MARTINS, L. P.; SILVA, S. M.; ALVES, R. E.; FILGUEIRAS, H. A. C.. Desenvolvimento de frutos de cirigueleira (Spondias purpurea L.). Revista Brasileira de Fruticultura, Jaboticabal, v.25, n.1, 2003.

MARTINS, S. T.; MELO, B.. Spondias (Cajá e outras). Uberlândia: 2003.

MERCADO-SILVA, E.; BAUTISTA, P.B.; GARCIAVELASCO, $M$. A.. Fruit development, harvest index ripening changes of guavas produced in central Mexico. Postharvest Biology and Technology, v.13, 1998.

MONÇÃO, E. C.; SILVA, E. F.; SOUSA, P. B.; SILVA, M. J. M.; SOUSA, M. M.. Avaliação físico-química e centesimal de polpas congeladas de cajá (Spondias mombin L.) E de manga (Mangifera indica L.) consumidas em Teresina-PI. Piauí, 2010.

NAVA-KURI, G. G., USCANGA, M. B.. Estudio fisico y quimico de doce tipos de ciruela (Spondias $s p$ ) en el estado de Vera Cruz. Tropical Region. v.23, 1979.

OMENA, C. M. B.; OLIVEIRA, M. B. F.; COSTA, J. G.; SANT'ANA, A. E. G.. Caracterização de frutos de 
ciriguleira (Spondias purpurea L.) comercializado em Maceió, Alagoas. In: CONGRESSO BRASILEIRO DE FRUTICULTURA, 20. Anais. Vitória, 2008.

SANTOS, E. O. C.. Enfoques sócio-econômicos da produção, processamento e comercialização do umbu no Semiárido brasileiro. In: Spondias no Brasil: umbu, cajá e espécies afins. Recife: UFPE, 2008.

SAUCEDO-VELOZ, C.; PÉREZ-LÓPEZ, A.; ARÉVALOGALARZA, M. L.; MURATALLA-LÚA, A.. Effect of the maturity stage on postharvest quality and shelf life in Mexican plum (Spondias purpurea L.) fruits. Revista Fitotecnia Mexicana, Chapingo, v.27, 2004.

SILVA, C.; RIBEIRO, A.; FERREIRA, D.; VEIGA, F.. Administração oral de peptídeos e proteínas: In: Aplicação de métodos de microencapsulação. Brazilian Journal of Pharmaceutical Sciences, São Paulo, 2003.

SOARES, E. S.. Caracterização de aditivos para Secagem de Araça-Boi (Eugenia stipitata Mc Vaugh) em Leito de Espuma. Itapetinga, 2009.

SOUZA, F. X.; ARAÚJO, C. A. T.. Avaliação dos métodos de propagação de algumas Spondias agroindustriais. Fortaleza: Embrapa Agroindústria Tropical, 1999.

SOUZA, V. R.; PEREIRA, P. A. P.; QUEIROZ, F.; BORGES, S. V.; CARNEIRO, J. D. S.. Determination of bioactive compounds, antioxidant activity and chemical composition of Cerrado. Food Chemistry, v.134, 2012.

VARGAS-SIMÓN, G.; HERNÁNDEZ-CUPIL, R.; MOGUELORDOÑEZ, E.. Caracterización morfológica de ciruela (Spondias purpurea L.) en tres municipios del estado de Tabasco. Bioagro, v.23, n.2, 2011. 